Valeria Bisogni, Giuseppe Maiolino, Giulio Ceolotto, Martino F. Pengo, Rosario Marchese Ragona, Carlo Artusi, Laura Brugnolo, Silvia Lerco, Daniele Borsetto, Piergiorgio Gaudioso, Alessandro Martini, Mario Plebani and Gian Paolo Rossi*

\title{
Design of a study to investigate the mechanisms of obstructive sleep apnoea by means of drug-induced sleep endoscopy
}

https://doi.org/10.1515/cclm-2019-0113

Received January 30, 2019; accepted March 23, 2019

\section{Abstract}

Background: Obstructive sleep apnoea (OSA) is an independent risk factor of hypertension and cardiovascular diseases. Recurrent episodes of upper airways collapse during sleep causing blood oxygen desaturation, hypercapnia, and micro-arousals, are known to activate the sympathetic nervous system (SNS). However, whether changes in the renin-angiotensin-aldosterone system and endothelial activation also occur remains contentious.

Methods: Based on routine use of drug-induced sleep endoscopy (DISE) for the work-up of OSA patients in our centre, we designed a prospective study to investigate the haemodynamic and humoral changes occurring during the apnoeic episodes reproduced in vivo in the course of DISE. Specifically, plasma aldosterone concentration and renin activity, C-terminal fragment of proendothelin-1, as a marker of endothelial damage, and free plasma catecholamines, will be measured at fixed times during DISE. The activity of catechol-O-methyltransferase (COMT), a key catecholamine-inactivating enzyme that has been scantly investigated thus far owing to the lack of commercially available kits, will be also determined by a newly

\footnotetext{
*Corresponding author: Gian Paolo Rossi, MD, FACC, FAHA, Department of Medicine, Clinica dell'Ipertensione Arteriosa, DIMED - University Hospital of Padova, Via Giustiniani, 2, 35126 Padova, Italy, Phone: +39-049-821-2279 or 7821, Fax: +39-049-8217873, E-mail: gianpaolo.rossi@unipd.it

Valeria Bisogni, Giuseppe Maiolino, Giulio Ceolotto and Silvia Lerco: Department of Medicine, Clinica dell'Ipertensione Arteriosa, DIMED - University Hospital of Padova, Padova, Italy Martino F. Pengo: Sleep Disorder Centre, Department of Cardiovascular, Neural and Metabolic Sciences, IRCCS Istituto Auxologico Italiano, Milan, Italy

Rosario Marchese Ragona, Daniele Borsetto, Piergiorgio Gaudioso and Alessandro Martini: Institute of Otolaryngology, Department of Neurosciences, University Hospital of Padova, Padova, Italy Carlo Artusi, Laura Brugnolo and Mario Plebani: Department of Laboratory Medicine, University Hospital of Padova, Padova, Italy
}

developed high performance liquid chromatography method, which is herein described.

Results and conclusions: The aim of this study is to provide novel information on the haemodynamic, hormonal, and SNS changes, and also on COMT activity modification concomitantly occurring during apnoea, thus contributing substantively to the understanding of the pathophysiology of OSA.

Keywords: catechol-O-methyltransferase; drug-induced sleep endoscopy; endothelin-1; obstructive sleep apnoea; renin-angiotensin-aldosterone system; sympathetic nervous system.

\section{Introduction}

Obstructive sleep apnoea (OSA) involves up to $13 \%$ of men and $6 \%$ of women, with prevalence on the rise owing to the ongoing epidemics of obesity [1-3]. In OSA patients recurrent episodes of total (apnoea) or partial (hypopnea) collapse of the upper airways, for at least $10 \mathrm{~s}$, occurring during sleep, are associated with blood oxygen desaturation, hypercapnia, and, consequently, with arousals from sleep to re-establish airway patency and normal respiration [4]. The latest European Societies of Cardiology and of Hypertension (ESC/ESH) [5] and the American Heart Association (AHA) [6] guidelines for arterial hypertension have finally recognized OSA as one of the most frequent forms of secondary and/or resistant hypertension, as well as an independent and modifiable risk factor for cardiovascular and metabolic complications $[2,7,8]$.

There are complex mechanisms involving multiple systems underlying the association of OSA with cardiovascular and metabolic disorders [2], among which the most important comprise the renin-angiotensin-aldosterone system (RAAS) [9], endothelial [10], and sympathoadrenergic activation [11, 12].

The role of catechol-O-methyltransferase (COMT), the main intracellular enzyme inactivating catecholamines (dopamine, epinephrine, and norepinephrine), but also 
other compounds bearing the catechol structure [13], is totally unknown in this context. Although the O-methylation of norepinephrine and epinephrine to their inactive products normetanephrine and metanephrine, respectively, is a major mechanism terminating the action of these sympathetic nervous system (SNS) mediators in different tissues [13], the role of COMT in the development of arterial hypertension in OSA subjects is unknown, as is the role of intermittent hypoxia, one of the main features of OSA, as a modulator of COMT activity. It is worth considering that COMT is widely present in human and animal tissues (i.e. central and peripheral nervous system, spleen, pancreatic cells, uterus, mammary glands, prostate, and chromaffin cells of adrenal glands $[14,15])$, with the highest quantity and activity, mRNA and protein distribution in the human liver hepatocytes and rat kidneys $[14,16]$, but with detectable expression also in red blood cells (RBCs) [17] and intestinal macrophages [18], where it is linked to the membrane. Hence, it is plausible that changes in arterial oxygen pressure and in haemoglobin oxygenation might influence COMT activity in the erythrocytes, and therefore, the circulating catecholamines metabolism.

Understanding the role of these substances and mechanisms has been hampered thus far by the impossibility of drawing blood without waking up the OSA patient. Of note, in ours as in other centres drug-induced sleep endoscopy (DISE) has become a routine test in the diagnostic work-up of OSA patients as it can allow precisely determining the site and severity of the airway obstruction and to plan treatment strategies [19, 20]. Furthermore, it allows the collecting of venous and arterial blood samples during different phases of the test, including apnoeic episodes in sleeping patients, and to correlate these biomarkers with the haemodynamic parameters, such as blood pressure (BP), heart rate (HR), and peripheral blood oxygen saturation.

Therefore, we set up a study to clarify the pathophysiology of OSA, to answer the following questions: (i) is there, during the apnoeic episodes, an increase of RAAS activation, adrenergic tone, and endothelial damage? (ii) Does intermittent hypoxia affect COMT activity and thereby lead to activation of the SNS?

\section{Materials and methods}

This is a single-centre, prospective, cohort study, in which we will enroll patients referred to our ESH Excellence Hypertension Centre, Department of Medicine, and to Otolaryngology Unit, Department of Neurosciences, University of Padua. The study flow-chart is summarised in Figure 1.

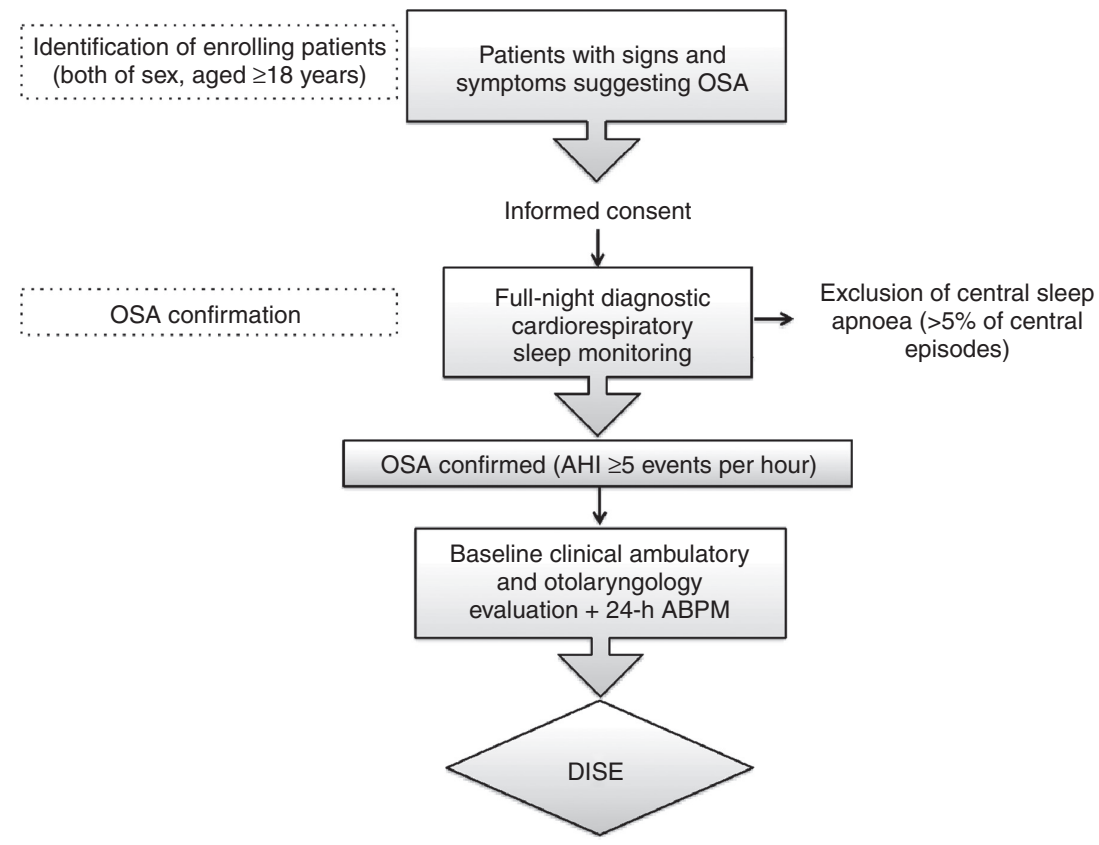

Figure 1: Flow-chart of the study.

OSA, obstructive sleep apnoea; AHI, apnoea/hypopnea index; 24-h ABPM, 24-h ambulatory blood pressure monitoring; DISE, drug-induced sleep endoscopy. 


\section{Ethical statement}

The study-protocol was approved by the Ethical Committee and the Institutional Review Board of University of Padova (protocol number 3217/AO/14). All procedures performed in studies involving human participants are in accordance with the ethical standards of the institutional and/or national research committee and with the 1964 Helsinki Declaration and its later amendments or comparable ethical standards. Informed consent will be obtained from all individual participants included in the study.

\section{Inclusion criteria}

- Symptoms and/or signs suggestive of OSA [21, 22], with indications to DISE to investigate the site of obstruction [19]:

(i) overweight and obesity (body mass index $[\mathrm{BMI}]>25 \mathrm{~kg} / \mathrm{m}^{2}$ );

(ii) neck circumference ( $>43 \mathrm{~cm}$ in men and $>41 \mathrm{~cm}$ in women);

(iii) night-time symptoms (e.g. snoring, apnoeic episodes documented by the partner, nocturnal chocking, dry mouth) and/or daytime symptoms (e.g. excessive daytime sleepiness, impaired concentration, morning headaches, loss of memory);

- A full-night diagnostic cardiorespiratory sleep monitoring demonstrating apnoea/hypopnea index (AHI) $\geq 5$ per h during sleep [23].

\section{Exclusion criteria}

- Craniofacial dysmorphisms and oropharyngeal abnormalities (e.g. micrognathia, retrognathia, macroglossia, mandibular hypoplasia);

- $\quad$ secondary forms of hypertension (e.g. primary aldosteronism [24], renovascular disease, pheochromocytoma [25], Cushing's syndrome [26]);

- acromegaly;

- $\quad$ acute kidney injury and chronic kidney diseases with estimated glomerular filtration rate (eGFR) CKD-EPI $<60 \mathrm{~mL} / \mathrm{min} / 1.73 \mathrm{~m}^{2}$ [27];

- treatment with beta-blockers and other drugs interfering with the SNS;

- $\quad$ type I and II diabetes mellitus;

- pregnancy;

- life expectancy <2 years;

- haemodynamic instability severe enough to require IV positive inotropic agents;

- comorbidity conditions limiting the execution of DISE;

- acute coronary syndromes within 4 weeks;

- unwillingness or inability to complete follow-up;

- patients with any serious medical condition, which in the opinion of the investigators, may adversely affect the safety of the participant;

- $\quad$ known history of unresolved drug use or alcohol dependency;

- current enrolment in another investigational drug or device trial.

All subjects enrolled in the study will undergo a full medical assessment, where past medical history and current medications will be recorded. Also, physical examinations will be performed and anthropometric data will be collected. Excessive daytime sleepiness will be evaluated through the Epworth Sleepiness Scale (ESS) [28]. The patients will be then screened to exclude a secondary hypertension diagnosis by measuring concentration of plasma aldosterone (PAC) and by a direct renin (DRC) chemiluminescent assay after an appropriate wash-out [24], and urinary 24-h catecholamines and metanephrines. Moreover, patients will undergo a renal artery and adrenal computed tomography scan and/or renal arteries computed tomography angiography, whenever appropriate.

All patients will be selected for DISE based on demonstration of OSA by means of cardio-respiratory monitoring (also defined "polygraphy study") and will undergo a 24-h ambulatory blood pressure monitoring (24-h ambulatory blood pressure monitoring [ABPM]).

\section{Obstructive sleep apnoea screening}

The full-night diagnostic cardiorespiratory sleep monitoring will be performed at home with portable devices using an Embletta ${ }^{\circledast}$ X 100 (Rembla, Natus, Pleasanton, CA, USA), which was previously validated for patients with suspected OSA [29]. Measurements obtained include nasal pressure, airflow by thermistor, respiratory effort by impedance plethysmography, sonography, and finger pulse-oximetry. The Embletta devices will be programmed to automatically begin recording at 22:00 and stop at 07:00. Based on sleep logs and out of centre sleep testing actigraphy (an intrinsic component of the Embletta system), the scoring technologist will modify the analysis start time and end time, resulting in a total registration time that approximates the total sleep time, as closely as possible. Respiratory events (apnoea and hypopnea) will be scored according to the American Academy of Sleep Medicine Scoring Manual [23]. Apnoea is defined as a cessation ( $\geq 90 \%)$ in airflow of at least $10 \mathrm{~s}$; hypopnea as a reduction in the amplitude of airflow $\geq 30 \%$ for at least $10 \mathrm{~s}$, followed by a decrease in oxygen saturation of $\geq 3 \%$. The AHI will be calculated as the total number of apnoeas plus hypopneas divided by the hours of sleep. OSA is defined as an AHI of at least 5 per $\mathrm{h}$ [23]. Patients with significant central sleep apnoea ( $>5 \%$ of events) will be excluded.

\section{4-h ambulatory blood pressure monitoring}

24-h ABPM will be performed using available BP monitoring recording device, the Spacelabs 90207 (SpaceLabs, Snoqualmi, WA, USA) [30]. The between-measurement intervals will be 15 min (daytime) and $20 \mathrm{~min}$ (night-time). During each recording, subjects are required to attend their usual daily activities, but to refrain from unusual physical exercise or behavioural challenges. Patients are also asked to report their main activities in a diary, including the time of meals, bed rest or sleep and awakening times. Only recordings rated of sufficient quality, i.e. including at least $70 \%$ of valid readings over the $24 \mathrm{~h}$ and at least two valid readings per hour during daytime and one valid reading per hour during night-time, will be considered for the final analysis. Day and night periods will be defined and corrected according to what will be reported by the patient in the diary. The average daytime period will be finally identified as the interval from 08:00 $\mathrm{h}$ to $23: 00 \mathrm{~h}$ and the night period as the interval from 23:00 $\mathrm{h}$ to $08: 00 \mathrm{~h}$.

All data will be acquired and analysed according to the current recommendations [31] to obtain: the average 24-h, day and night 
systolic (SBP) and diastolic (DBP) blood pressure. The degree of nocturnal BP fall and the standard deviations (SDs) of the mean of all individual readings over the different time periods will be also considered. Based on the degree of nocturnal BP fall, subjects are classified as dippers (BP fall $\geq 10 \%$ and $<20 \%$ of daytime average BP) or non-dippers (fall $<10 \%$ ), separately for SBP and for DBP. Nocturnal BP fall $\geq 20 \%$ and $<0 \%$ identifies "extreme" dipper and "reverse dipper" subjects.

\section{Drug-induced sleep endoscopy}

DISE is currently used at our institution as a routine diagnostic test in patients with OSA to reproduce a condition of non-rapid eye movements sleep, during which examining the pharyngeal structures, recognising the exact site of upper airway obstruction [20], and identifying patients that would benefit from surgery [19]. The whole procedure is executed according to the current guidelines [19]. Briefly, it is performed in a semi-dark and silent operating room, by an experienced otolaryngologist with the patient lying supine. Drug-induced sleep is achieved with intravenous administration of propofol [32], with a target-controlled infusion rate after an initial loading dose. The electrocardiogram, BP, and peripheral oxygen saturation are continuously monitored by both the surgeon and the anaesthesiologist. A flexible endoscope is used to sequentially observe the nasal cavity, nasopharynx, velum, oropharynx, tongue base, and epiglottis.

During DISE, blood tests will be performed as illustrated in Figure 2. Specifically, we will collect the first blood sample (T-1) before sedation; after propofol infusion via e.v. (T0) we will proceed with the second one. The third blood sample (T1) will be obtained at the occurrence of the first obstructive apnoea, immediately after $10 \mathrm{~s}$ of upper airway occlusion as determined by the otolaryngologist; the upper airway is then kept patent through a mandibular protrusion manoeuvre. Then T2, T3, and T4 will be collected at $30 \mathrm{~s}$, $2 \mathrm{~min}$, and $5 \mathrm{~min}$ with the patient breathing normally in the absence of any other upper airway obstruction. Oxygen saturation (including minimum oxygen saturation after the first apnoea), HR, and BP will be recorded throughout the procedure. The last sample (T5) will be obtained 15 min after the apnoea.

Blood samples will be obtained using a syringe through a previously placed intravenous line and stored in Vacutainers containing ethylenediaminetetraacetic acid (EDTA). Samples will be centrifuged
( $\left.4^{\circ} \mathrm{C}, 2500 \mathrm{rpm}, 15 \mathrm{~min}\right)$. The RBCs $(400 \mu \mathrm{L})$ obtained, within $1 \mathrm{~h}$ will be transferred in a $1.5 \mathrm{~mL}$ tube, containing $200 \mu \mathrm{L}$ of RIPA buffer (25 mM Tris $\mathrm{HCl} \mathrm{pH} \mathrm{7.6,} 150 \mathrm{mM} \mathrm{NaCl}, 1 \%$ Triton X-100, 1\% sodium deoxycholate, $0.1 \%$ SDS and protease inhibitors) and centrifuged briefly. When lysis is complete, the tubes will be left on ice and eventually stored at $-80^{\circ} \mathrm{C}$.

For each sample we will perform an analysis of PAC and DRC, plasma catecholamines, COMT activity on RBCs, and plasma C-terminal fraction of pro endothelin-1 (CT-pro ET-1), in our laboratory.

\section{Assessment of renin-angiotensin-aldosterone system}

In each blood sample we will measure PAC and DRC, using a validated dual aldosterone and direct active renin concentration chemiluminescent commercially available assay in an automated analyser (Aldo LIAISON ${ }^{\circledR}$ MOME; DRC LIAISON ${ }^{\circledR}$ MOME; DiaSorin, Saluggia, Italy). Measurements will be performed on a LIAISON XL Analyser [33]. The elevation of renin is defined as a level $>33.5 \mathrm{mU} / \mathrm{L}$ and that of aldosterone as $>0.45 \mathrm{nmol} / \mathrm{L}$. The elevation of aldosterone-renin ratio (ARR) is defined $>2.06 \mathrm{nmol} / \mathrm{dL} / \mathrm{mUI} / \mathrm{L}$.

\section{Endothelial function}

The endothelial cell-derived vasoconstrictor ET-1, a 21-amino acid peptide, the most abundant member of the endothelins family, is secreted abluminally by about $80 \%$. It acts in an autocrine and/or paracrine manner by binding to $\mathrm{ET}_{\mathrm{A}}$ receptors on the underlying smooth muscle cells, including those of the pulmonary circulation, where it causes potent vasoconstriction $[34,35]$. The promoter region of the prepro $(P P)-E T-1$ gene is known to harbour hypoxia-responsive elements, mediating enhanced PP-ET-1 mRNA transcription, and, thereby, ET-1 synthesis in response to hypoxia [35, 36]. Hence, ET-1 is held to play a major role in pulmonary arterial hypertension and, accordingly, ET-1 receptor antagonists have become a milestone in the treatment of pulmonary arterial hypertension [37]. Thus far, the assessment of ET-1 activation in OSA has been hampered not only by its abluminal secretion but, even more so, by its very short (1-2 min) plasma half-life, its immediate clearance through $\mathrm{ET}_{\mathrm{B}}$ receptor binding and cleavage by neutral endopeptidases. Therefore, as estimation of ET-1 release from

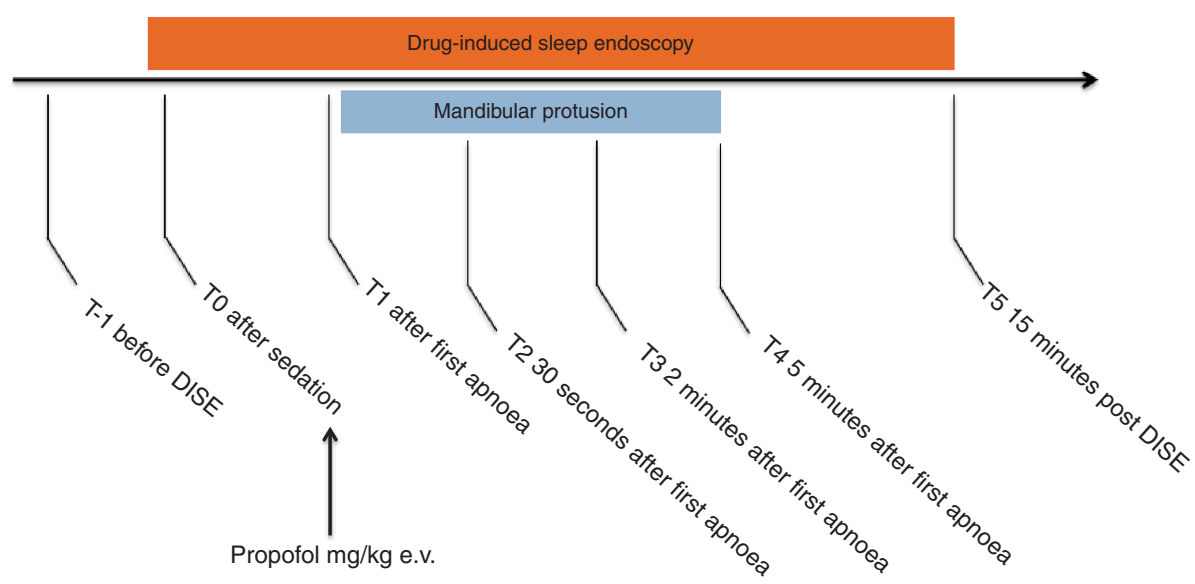

Figure 2: Timing of blood tests that will be performed before, during, and after drug-induced sleep endoscopy (DISE). 
endothelial cells is held to be extremely challenging, in this study we will measure the C-terminal fragment of proET-1 (CT-proET-1), which represents a better proxy for ET-1 biosynthesis as it is more stable than mature ET-1 and is not subject to rapid turnover [36].

\section{Plasma catecholamines and catechol-0-methyl-trans- ferase activity}

The plasma levels of epinephrine and norepinephrine will be determined by high-pressure liquid chromatography (HPLC) assay coupled with electrochemical detection using Chromsystems 5000 ${ }^{\circledR}$ kit (Chromsystems Instruments \& Chemicals, Germany).

Given the lack of commercial kits to measure COMT activity, we developed a HPLC with an electrochemical detection (ECD) method for estimating COMT activity using 3,4-dihydroxybenzylamine (DHBA), a catecholamine analogue [38], as a substrate, and measuring its products (vanillic and isovanillic acids) in the supernatant. The chromatographic system consists of a solvent delivery system CLC300 (Chromsystems), a programmable autosampler CLC200 (Chromsystems) and an ECD CLC100 (Chromsystems). A Discovery ${ }^{\circledR}$ C18 HPLC column $(15 \mathrm{~cm} \times 4.6 \mathrm{~mm}, 5 \mu \mathrm{m}$, SUPELCO $)$ at $25^{\circ} \mathrm{C}$ was used as an analytical column. A glassy carbon working electrode was set at 0.90 vs. an $\mathrm{Ag} / \mathrm{AgCl}$ reference electrode with a sensitivity set at $20 \mathrm{nA}$. The mobile phase consisted of the buffer disodium hydrogen phosphate (0.1 M) and EDTA (0.15 mM) methanol (80:20, v/v), the pH was adjusted to 3.2 with phosphoric acid. The flow rate was $0.8 \mathrm{~mL} / \mathrm{min}$. The injection volume of the standard solution and the supernatant was set at $20 \mu \mathrm{L}$. COMT activity was expressed as pmol of vanillic $\mathrm{acid} / \mathrm{min} / \mathrm{mg}$ protein. Protein measurement was performed using a Quantum Protein kit (Euroclone, Milan, Italy), which is a formulation based on bicinchoninic acid (BCA) allowing a rapid identification of protein content.

This method will be applied to measure COMT activity in RBCs and macrophages isolated from each sample collected during DISE. A set of preliminary experiments performed in blood samples from healthy donors showed the feasibility of this approach.

In more detail, we prepared a buffer solution $(400 \mu \mathrm{L})$ containing: (i) phosphate buffer preparation ( $\mathrm{pH} 7.4250 \mathrm{mM}$ ) to keep $\mathrm{pH}$ levels within the normal range in order for the enzyme to remain active, (ii) $\mathrm{MgCl}_{2} 6.25 \mathrm{mM}$ as a catalyst of electron exchange, (iii) s-adenosylmethionine (2.5 mM) as a methyl group donor, (iv) and DHBA $0.5 \mathrm{mM}$ as a substrate. The enzyme reaction was started by adding $200 \mu \mathrm{L}$ of the RBCs lysis solution to the buffer solution and incubated for $45 \mathrm{~min}$ at $37^{\circ} \mathrm{C}$. Tubes were then placed on ice and $\mathrm{HClO}_{4}$ $4 \mathrm{M}(150 \mu \mathrm{L})$ was added to obtain protein precipitation. Tubes were centrifuged at $10,000 \mathrm{rpm}(8,000 \times \mathrm{g})$ for $15 \mathrm{~min}$ at $4^{\circ} \mathrm{C}$ and supernatant was collected and transferred to new $1.5 \mathrm{~mL}$ tubes and stored at $-80^{\circ} \mathrm{C}$ for further quantification of vanillic acid by the HPLC method.

The intra- and inter-assay precisions were determined using the coefficient of variation (CV, \%), and the intra- and inter-assay accuracies were expressed as the percent difference between the measured concentration and the nominal concentration. The intra-assay CV was evaluated by performing 10 tests on samples containing two different substrate concentrations (DHBA at 0.50 and $0.02 \mathrm{mM}$ ). The vanillic acid CV values were $5.9 \%$ and $9.3 \%$ for DHBA concentrations of $0.50 \mathrm{mM}$ and $0.02 \mathrm{mM}$, respectively; for isovanillic acid they were $7.5 \%$ and $12.9 \%$ for the same substrate concentrations. The assessment of reproducibility (inter-assay CV) was carried out, as for repeatability, through 10 determinations of two samples containing two different concentrations of substrate (DHBA at 0.50 and $0.02 \mathrm{mM}$ ); the vanillic acid CV were $7.5 \%$ and $9.7 \%$ for concentrations of DHBA of $0.50 \mathrm{mM}$ and $0.02 \mathrm{mM}$, respectively, for isovanillic acid CV $1.7 \%$ and $13.6 \%$ at the same substrate concentrations.

Six standard solutions (at concentrations of $0.05,0.10,0.20$, $0.50,1.00,2.00 \mu \mathrm{M}$ ) were used to perform the analysis of linearity of the standard calibration curve. The determination of the limit of quantitation, evaluated experimentally, allowed to demonstrate that for concentration of $0.10 \mu \mathrm{M}$ a signal corresponding to 10 times the standard deviation of the signal-to-noise was obtained.

\section{Power calculation and statistical analysis}

We calculated the sample size required for this study by considering two experimental end-points, i.e. PAC and COMT activity. Considering a 20\% change in either parameter as biologically relevant, and a two-sided 0.05 significance level, a total of 36 patients warranted a $90 \%$ power of detecting a $20 \%$ change of both end-point variables occurring after the first apnoea during DISE, as compared to PAC before the procedure if the true mean after logarithmic transformation is 5.75, based on the assumption that the within-patient standard deviation of the mean PAC value is 1.5 (paired t-test).

Data will be tested for Gaussian distribution with the Kolmogorov-Smirnov test. If required, a Gaussian distribution will be achieved by log or square root transformation of skewed variables. Comparison of quantitative variables across different time points will be carried out by a one-way within-subject ANOVA followed by Bonferroni's post-hoc test. Data will be reported as mean and standard deviation (SD) or median plus interquartile range (IQR) if not normally distributed. Statistical significance will be defined as $\mathrm{p}<0.05$. SPSS $^{\text {TM }}$ version 22.0 for Mac (IBM, USA) and GraphPad Prism software $^{\mathrm{TM}}$ (version 8.0 for Mac, GraphPad Software Inc., San Diego, CA, USA) will be used for all analysis.

\section{Results}

\section{Preliminary results}

We have explored the feasibility of measuring COMT activity in RBCs and macrophages of a healthy subject (age 24 years old, BMI $25.1 \mathrm{~kg} / \mathrm{m}^{2}$ ) during in vitro exposure to hypoxia. Moreover, in order to understand whether propofol could exert an inhibiting or stimulating effect on COMT activity, we measured this latter in RBCs and macrophages, from the same donor, incubated with propofol itself.

We used a hypoxia incubator chamber (with an internal atmosphere consisting of $4 \% \mathrm{O}_{2}, 6 \% \mathrm{CO}_{2}$, and $90 \%$ $\mathrm{N}_{2}$ ), in which we incubated a culture medium RPMI 1640 diluted with phosphate buffered saline (PBS) for 1 night. The day after, $500 \mu \mathrm{L}$ of RBCs were placed into a dish and then introduced into the hypoxia chamber where they were diluted with $1 \mathrm{~mL}$ of PBS. After 2, 5, 15, 30 and 60 min of incubation, the RBCs were centrifuged, lysed, 
and stored at $-80^{\circ} \mathrm{C}$. The same experiment was conducted on macrophages. COMT activity was measured with HPLC with ECD, as described in the Methods section.

The results showed that in both RBCs and macrophages the enzymatic activity significantly increased after 30 and $60 \mathrm{~min}$ of hypoxic incubation, as shown in Figure 3, panels A and B. On the contrary, the RBCs incubation at $37^{\circ} \mathrm{C}$ with propofol $(1 \mathrm{mmol})$ did not induce any detectable change of activity after 5, $10 \mathrm{~min}$ and $1 \mathrm{~h}$ (data not shown).

\section{Discussion}

OSA is a worldwide health problem and, when moderate-to-severe (AHI $\geq 15$ events/h), entails a potentially fatal disease associated not only with increased risk of cardiovascular and metabolic diseases [2, 3], but also with motor vehicle accidents due to excessive sleepiness and impaired concentration [39]. Among the pathogenic mechanisms underlying the association between OSA and cardiovascular and metabolic diseases, activation of the RAAS, the SNS, and the endothelin-1 system play a key role [2]. Of note, ET-1 has been reported to deeply interact with the RAAS at multiple levels [40] and to contribute substantively to angiotensin II-inducing cardiovascular and renal damage [41-43]. However, in the pathogenesis of arterial hypertension and cardiovascular morbidity in OSA patients, the role of COMT, the main peripheral enzyme involved in the SNS modulation and catecholamines catabolism, has not been clarified. Especially, it has been not verified whether its activity might be modulated by the increased plasma catecholamine levels and/or directly by the lower oxygenation of peripheral tissues, including red blood cells and macrophages (as was highlighted by our preliminary results), which occurs during apnoea.

Nonetheless, the precise mechanisms whereby these systems contribute to the development of hypertension and cardiometabolic complications in OSA remain somewhat contentious, mainly because of the impossibility of undertaking their measurements during apnoea without waking the patient and triggering a stress reaction. It is likely that this bias might have affected previous studies, aimed at clarifying the pathophysiology of cardiovascular damage in spontaneously occurring OSA $[8,40]$.

Our study is, therefore, novel and provides the opportunity to concomitantly assess in humans in vivo, in the laboratory under standardized conditions, the haemodynamic and blood gas changes, alongside variations of several key molecules that are putatively involved in OSA during apnoea. In fact, DISE mimics the non-rapid eye movements sleep phase through the administration of sedatives [19] and provides an opportunity for collecting blood samples, without waking patients and inducing a sudden alert reaction and sympathetic activation.

Hence, the hypothesis that, during apnoea in vivo there is an activation of the renin-angiotensin-aldosterone system, endothelial, and SNS secondary to hypoxia, can be confirmed or challenged by this protocol. Moreover, this study is the first to assess the changes in COMT activity and, therefore, to determine if it plays a role in modulating cardiovascular and metabolic risk in obstructive sleep apnoea patients.

Author contributions: All the authors have accepted responsibility for the entire content of this submitted manuscript and approved submission.

Conflict of interest: The authors declare that they have no conflict of interest.
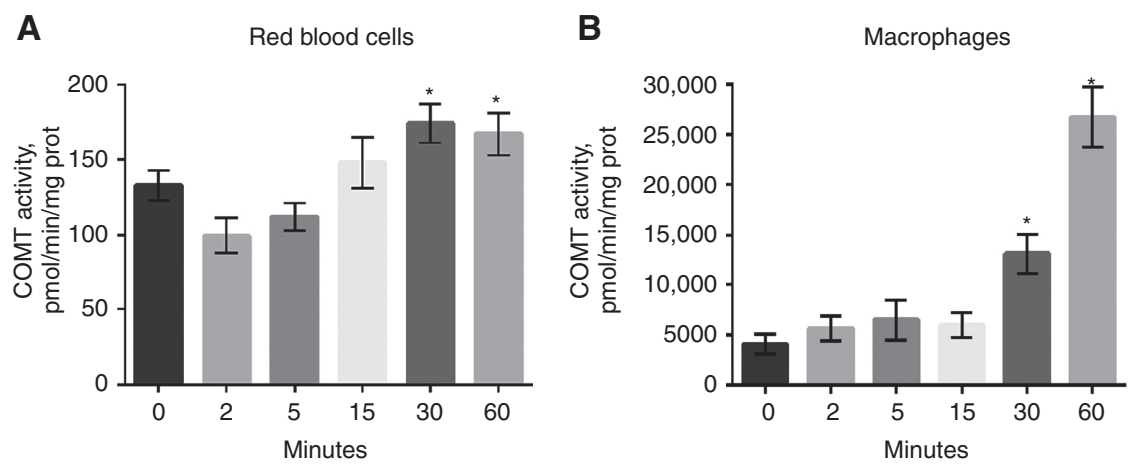

Figure 3: Catechol-0-methyl transferase (COMT) activity in red blood cells (A) and macrophages (B) after hypoxic incubation. To evaluate the effect of hypoxia on COMT activity we measured this latter in red blood cells and macrophages from healty human donor. The bar graphs show as in both cell types after 30 and $60 \mathrm{~min}$ of hypoxia $\left(4 \%\right.$ of $\left.\mathrm{O}_{2}\right)$ COMT activity was significantly high compared to the first minutes of experiment. ${ }^{*} \mathrm{p}<0.01$. 
Research funding: Grant support: FORICA (The FOundation for advanced Research In Hypertension and CArdiovascular diseases), the Società Italiana dell'Ipertensione Arteriosa and the University of Padua to GPR. Research grant by the Young Research Program of the Italy's Health Minister to L.L. Project GR-2009 -1524351. No relationship with industry to be disclosed.

Employment or leadership: None to declare.

Honorarium: None to declare.

Competing interests: The funding organisation played no role in the study design; in the collection, analysis, and interpretation of data; in the writing of the report; or in the decision to submit the report for publication.

\section{References}

1. Peppard PE, Young T, Barnet JH, Palta M, Hagen EW, Hla KM. Increased prevalence of sleep-disordered breathing in adults. Am J Epidemiol 2013;177:1006-14.

2. Javaheri S, Barbe F, Campos-Rodriguez F, Dempsey JA, Khayat R, Javaheri S, et al. Sleep apnea: types, mechanisms, and clinical cardiovascular consequences. J Am Coll Cardiol 2017;69:841-58.

3. Steier J, Lunt A, Hart N, Polkey MI, Moxham J. Observational study of the effect of obesity on lung volumes. Thorax 2014;69:752-9.

4. Javaheri S. Cardiovascular diseases. In: Kryger MH, Avidan AY, Berry RB, editors. Atlas of Clinical Sleep Medicine, 2nd ed. Philadelphia, PA: Saunders, 2014:316-28.

5. Williams B, Mancia G, Spiering W, Agabiti Rosei E, Azizi M, Burnier M, et al. ESC Scientific Document Group. 2018 ESC/ESH Guidelines for the management of arterial hypertension. Eur Heart J 2018;39:3021-104.

6. Whelton PK, Carey RM, Aronow WS, Casey DE Jr, Collins KJ, Dennison Himmelfarb C, et al. 2017 ACC/AHA/AAPA/ABC/ACPM/ AGS/APhA/ASH/ASPC/NMA/PCNA Guideline for the prevention, detection, evaluation, and management of high blood pressure in adults: executive summary: a Report of the American College of Cardiology/American Heart Association Task Force on Clinical Practice Guidelines. Circulation 2018;138:e484-594.

7. Parati G, Lombardi C, Hedner J, Bonsignore MR, Grote L, Tkacova R, et al. EU COST Action B26 members. Recommendations for the management of patients with obstructive sleep apnoea and hypertension. Eur Respir J 2013;41:523-38.

8. Somers VK, White DP, Amin R, Abraham WT, Costa F, Culebras A, et al. American Heart Association Council for High Blood Pressure Research Professional Education Committee, Council on Clinical Cardiology; American Heart Association Stroke Council; American Heart Association Council on Cardiovascular Nursing; American College of Cardiology Foundation. Sleep apnea and cardiovascular disease: an American Heart Association/american College Of Cardiology Foundation Scientific Statement from the American Heart Association Council for High Blood Pressure Research Professional Education Committee, Council on Clinical Cardiology, Stroke Council, and Council on Cardiovascular Nursing. In collaboration with the National Heart, Lung, and Blood Institute National Center on Sleep Disorders Research (National Institutes of Health). Circulation 2008;118:1080-111.
9. Prejbisz A, Kołodziejczyk-Kruk S, Lenders JW, Januszewicz A. Primary aldosteronism and obstructive sleep apnea: is this a bidirectional relationship? Horm Metab Res 2017;49:969-76.

10. Phillips B, Narkiewicz K, Pesek CA, Haynes WG, Dyken ME, Somers VK. Effects of obstructive sleep apnea on endothelin-1 and blood pressure. J Hypertens 1999;17:61-6.

11. Mansukhani MP, Kara T, Caples SM, Somers VK. Chemoreflexes, sleep apnea, and sympathetic dysregulation. Curr Hypertens Rep 2014;16:476.

12. Bisogni V, Pengo MF, Maiolino G, Rossi GP. The sympathetic nervous system and catecholamines metabolism in obstructive sleep apnoea. J Thorac Dis 2016;8:243-54.

13. Eisenhofer G, Kopin IJ, Goldstein DS. Catecholamine metabolism: a contemporary view with implications for physiology and medicine. Pharmacol Rev 2004;56:331-49.

14. Myöhänen TT, Schendzielorz N, Männistö PT. Distribution of catechol-0-methyltransferase (COMT) proteins and enzymatic activities in wild-type and soluble COMT deficient mice. J Neurochem 2010;113:1632-43.

15. Axelrod J, Albers W, Clemente CD. Distribution of catechol-Omethyl transferase in the nervous system and other tissues. J Neurochem 1959;5:68-72.

16. Tsunoda M, Takezawa K, Masuda M, Imai K. Rat liver and kidney catechol-0-methyltransferase activity measured by high-performance liquid chromatography with fluorescence detection. Biomed Chromatogr 2002;16:536-41.

17. Ellingson T, Duddempudi S, Greenberg BD, Hooper D, Eisenhofer $\mathrm{G}$. Determination of differential activities of soluble and membrane-bound catechol-0-methyltransferase in tissues and erythrocytes. J Chromatogr B Biomed Sci Appl 1999;729:347-53.

18. Inoue K, Creveling CR. Immunocytochemical localization of catechol-0-methyltransferase in the oviduct and in macrophages in corpora lutea of rat. Cell Tissue Res 1986;245:623-8.

19. De Vito A, Carrasco Llatas M, Vanni A, Bosi M, Braghiroli A, Campanini A, et al. European position paper on drug-induced sedation endoscopy (DISE). Sleep Breath 2014;18:453-65.

20. Croft CB, Pringle M. Sleep nasendoscopy: a technique of assessment in snoring and obstructive sleep apnoea. Clin Otolaryngol Allied Sci 1991;16:504-9.

21. Epstein LJ, Kristo D, Strollo PJ Jr, Friedman N, Malhotra A, Patil SP, et al. Adult Obstructive Sleep Apnea Task Force of the American Academy of Sleep Medicine. Clinical guideline for the evaluation, management and long-term care of obstructive sleep apnea in adults. J Clin Sleep Med 2009;15:263-76.

22. Qaseem A, Holty JE, Owens DK, Dallas P, Starkey M, Shekelle P. Clinical Guidelines Committee of the American College of Physicians. Management of obstructive sleep apnea in adults: A clinical practice guideline from the American College of Physicians. Ann Intern Med 2013;159:471-83.

23. American Academy of Sleep Medicine. The AASM Manual for the Scoring of Sleep and Associated Events: Rules, Terminology and Technical Specifications, Version 2.4. www.aasmnet.org. Darien, Illinois: American Academy of Sleep Medicine, 2017.

24. Rossi GP, Bernini G, Caliumi C, Desideri G, Fabris B, Ferri C, et al. PAPY Study Investigators. A prospective study of the prevalence of primary aldosteronism in 1,125 hypertensive patients. J Am Coll Cardiol 2006;48:2293-300.

25. Lenders JW, Duh QY, Eisenhofer G, Gimenez-Roqueplo AP, Grebe SK, Murad MH, et al. Endocrine Society. Pheochromocytoma and 
paraganglioma: an endocrine society clinical practice guideline. J Clin Endocrinol Metab 2014;99:1915-42.

26. Nieman LK, Biller BM, Findling JW, Newell-Price J, Savage MO, Stewart PM, et al. The diagnosis of Cushing's syndrome: an Endocrine Society Clinical Practice Guideline. J Clin Endocrinol Metab 2008;93:1526-40.

27. National Kidney Foundation. K/DOQI Clinical Practice Guidelines for Chronic Kidney Disease: Evaluation, Classification and Stratification. Am J Kidney Dis 2002;39(suppl 1):S1-266.

28. Johns MW. A new method for measuring daytime sleepiness: the Epworth sleepiness scale. Sleep 1991;14:540-5.

29. Ng SS, Chan TO, To KW, Ngai J, Tung A, Ko FW, et al. Validation of Embletta portable diagnostic system for identifying patients with suspected obstructive sleep apnoea syndrome (OSAS). Respirology 2010;15:336-42.

30. Groppelli A, Omboni S, Parati G, Mancia G. Evaluation of noninvasive blood pressure monitoring devices Spacelabs 90202 and 90207 versus resting and ambulatory 24 -hour intra-arterial blood pressure. Hypertension 1992;20:227-32.

31. O’Brien E, Asmar R, Beilin L, Imai Y, Mallion JM, Mancia G, et al. European Society of Hypertension Working Group on Blood Pressure Monitoring. European Society of Hypertension recommendations for conventional, ambulatory and home blood pressure measurement. J Hypertens 2003;21:821-48.

32. Fulton B, Sorkin EM. Propofol. An overview of its pharmacology and a review of its clinical efficacy in intensive care sedation. Drugs 1995;50:636-57.

33. Rossi GP, Ceolotto G, Rossitto G, Seccia TM, Maiolino G, Berton C, et al. Prospective validation of an automated chemiluminescence-based assay of renin and aldosterone for the work-up of arterial hypertension. Clin Chem Lab Med 2016;54:1441-50.

34. Masaki T. Historical review: Endothelin. Trends Pharmacol Sci 2004;25:219-24.
35. Yanagisawa M, Kurihara H, Kimura S, Tomobe $Y$, Kobayashi M, Mitsui Y, et al. A novel potent vasoconstrictor peptide produced by vascular endothelial cells. Nature 1988;332:411-5.

36. Papassotiriou J, Morgenthaler NG, Struck J, Alonso C, Bergmann A. Immunoluminometric assay for measurement of the C-terminal endothelin-1 precursor fragment in human plasma. Clin Chem 2006;52:1144-51.

37. Rubin LJ, Badesch DB, Barst RJ, Galie N, Black CM, Keogh A, et al. Bosentan therapy for pulmonary arterial hypertension. N Engl J Med 2002;346:896-903.

38. Nissinen E, Männistö PT. Biochemistry and pharmacology of catechol-0-methyltransferase inhibitors. Int Rev Neurobiol 2010;95:73-118.

39. Tregear S, Reston J, Schoelles K, Phillips B. Obstructive sleep apnea and risk of motor vehicle crash: systematic review and meta-analysis. J Clin Sleep Med 2009;5:573-81.

40. Rossi GP, Sacchetto A, Cesari M, Pessina AC. Interactions between endothelin-1 and the renin-angiotensin-aldosterone system. Cardiovasc Res 1999;43:300-7.

41. Seccia TM, Caroccia B, Gioco F, Piazza M, Buccella V, Guidolin D, et al. Endothelin-1 drives epithelial-mesenchymal transition in hypertensive nephroangiosclerosis. J Am Heart Assoc 2016;5:pii: e003888.

42. Seccia TM, Belloni AS, Kreutz R, Paul M, Nussdorfer GG, Pessina AC, et al. Cardiac fibrosis occurs early and involves endothelin and AT-1 receptors in hypertension due to endogenous angiotensin II. J Am Coll Cardiol 2003;41: 666-73.

43. Seccia TM, Maniero C, Belloni AS, Guidolin D, Pothen P, Pessina AC, et al. Role of angiotensin II, endothelin-1 and L-type calcium channel in the development of glomerular, tubulointerstitial and perivascular fibrosis. J Hypertens 2008;26:2022-9. 